\title{
Learning mechanisms for DA-modulated spiking networks in the basal ganglia
}

\author{
Simon M Vogt, Ulrich G Hofmann \\ From Nineteenth Annual Computational Neuroscience Meeting: CNS*2010 \\ San Antonio, TX, USA. 24-30 July 2010
}

How the basal ganglia act to gate cortically planned actions is a topic of current discussion. Interesting work by Gurney et al [1-3] suggests an interaction between the STN and GPe as a central element of inhibition for action gating, with pathological oscillations occurring if striatal input changes due to dopamine depletion in Parkinson's disease.

But what exactly changes in the signals that the striatum projects to the rest of the basal ganglia? How could the altered dopamine signal and its effect on striatal learning influence the observed functions of the basal ganglia in Parkinsonian and in healthy patients?

While rate-based learning models of the basal ganglia have been suggested [5], a spiking network that reproduces basal ganglia anatomy and autonomously learns a set of possible action sequences that can then be reinforced through dopamine feedback has yet to be demonstrated.

On the way to constructing such a network, we present some effects of spike timing dependent plasticity, synaptic delay, group inhibition, noisy \& localised projections and dopamine modulation on feed-forward and associative spiking networks within the basal ganglia and cortex.
4. Cisek P: Cortical mechanisms of action selection: the affordance competition hypothesis. Philos Trans R Soc Lond B Biol Sci 2007, 362:1585-1599.

5. Frank MJ: Dynamic dopamine modulation in the basal ganglia: a neurocomputational account of cognitive deficits in medicated and nonmedicated Parkinsonism. J Cogn Neurosci 2005, 17:51-72.

6. Schultz W: Multiple reward signals in the brain. Nature Reviews Neuroscience 2000, 1:199-207.

7. Farries MA, Fairhall AL: Reinforcement learning with modulated spike timing dependent synaptic plasticity. Journal of neurophysiology 2007, 98:3648-65.

8. Masquelier T, Guyonneau R, Thorpe SJ: Competitive STDP-based spike pattern learning. Neural Computation 2009, 21:1259-76.

9. Potjans W, Morrison A, Diesmann M: A spiking neural network model of an actor-critic learning agent. Neural computation 2009, 21:301-39.

10. Singh SP, Barto AG, Chenanez N: Intrinsically motivated reinforcement learning. Advances in Neural Information Processing Systems 2005, 17:1281-1288.

\section{doi:10.1186/1471-2202-11-S1-P106}

Cite this article as: Vogt and Hofmann: Learning mechanisms for DAmodulated spiking networks in the basal ganglia. BMC Neuroscience 2010 11(Suppl 1):P106.

\section{References}

1. Gurney K, Prescott TJ, Redgrave P: A computational model of action selection in the basal ganglia. I. A new functional anatomy. Biol. Cybern 2001, 84:401-410.

2. Humphries MD, Stewart RD, Gurney $\mathrm{KN}$ : A physiologically plausible model of action selection and oscillatory activity in the basal ganglia. J Neurosci 2006, 26:12921-42.

3. Bogacz R, Gurney K: The basal ganglia and cortex implement optimal decision making between alternative actions. Neural Comput 2007, 19:442-477.

\footnotetext{
* Correspondence: vogt@isip.uni-luebeck.de

Institute for Signal Processing, University of Lübeck, Lübeck, 23538, Germany
}

Submit your next manuscript to BioMed Central and take full advantage of:

- Convenient online submission

- Thorough peer review

- No space constraints or color figure charges

- Immediate publication on acceptance

- Inclusion in PubMed, CAS, Scopus and Google Scholar

- Research which is freely available for redistribution
C Biomed Central 